\title{
Hypoxanthine, xanthine, and urate in synovial fluid from patients with inflammatory arthritides
}

\author{
Björn Gudbjörnsson, Andrej Zak, Frank Niklasson, Roger Hällgren
}

\begin{abstract}
As nucleotide catabolism increases during tissue injury the appearance of purine metabolites in inflamed synovial fluid might be of value in understanding the joint damage in inflammatory athritides. In this study, therefore, synovial and plasma concentrations of hypoxanthine, xanthine, and urate in 16 patients with rheumatoid arthritis (three with psoriatic arthropathy) were analysed. It was found that their plasma concentrations of hypoxanthine were greater than those of a reference group of healthy subjects. The synovial fluid concentrations of hypoxanthine, xanthine, and urate were higher than corresponding concentrations in plasma. Positive correlations were found between the respective plasma and synovial fluid values of xanthine and urate. These findings indicate a local enhanced purine metabolism in inflamed joint tissue and diffusion of oxypurines from joint cavity to plasma. No relation was found between measured metabolites and disease duration, radiological joint findings, or synovial fluid cells. Except for a weak correlation between plasma urate and serum haptoglobin, measured purine metabolites were not related to laboratory measures of systemic inflammation.
\end{abstract}

Joint damage is an important consequence of rheumatoid arthritis and other inflammatory athritides and accounts for functional impairment and disability. The traditional view is that inflammation is the major mechanism behind the joint destruction. Therefore, the main attraction has been directed towards various inflammatory mediators. In clinical practice several indices of inflammatory activity, such as erythrocyte sedimentation rate and acute phase plasma proteins, have been considered as valuable markers. These estimates of disease activity cannot be considered as reliable predictors of progressive joint damage, however. ${ }^{1-3}$ Thus novel markers for an understanding of the disease process are urgently needed. It has been suggested that joint damage may result from a series of pathological changes unrelated to the inflammation. ${ }^{48}$ Metabolically unfavourable effects on the joint structures might be secondary to altered nutrition or ischaemia, for example, and could be reflected by purine metabolites. In a previous study increased synovial fluid concentrations of hypoxanthine were reported in patients with rheumatoid arthritis. ${ }^{9}$ In an attempt to elucidate further the nucleotide metabolism within the inflamed joint cavity we measured the synovial fluid concentrations of the oxypurines hypoxanthine, xanthine, and urate in patients with inflammatory arthritides. Data obtained were related to the inflammatory activity and clinical symptoms, disease duration, and radiological joint changes.

\section{Patients and methods}

Ten women and six men with destructive and symmetric polyarthritis were included in the study. Eleven patients fulfilled the criteria of the American Rheumatism Association ${ }^{10}$ for classical rheumatoid arthritis. Two patients had juvenile rheumatoid arthritis. Three patients had seronegative polyarthritis associated with psoriasis. Their mean age was 42.6 years (range 21-68) and the mean disease duration was nine years (range six months to 18 years). All patients were taking non-steroidal anti-inflammatory drugs or aspirin and seven patients were treated with sulphasalazine. Table 1 presents the clinical data. Subjective clinical symptomsmorning stiffness and joint pain in the aspirated knee-and objective symptoms of active arthritis-degree of heat in the skin and grade of knee effusion-were estimated. These symptoms were graduated as mild, slight, moderate, or severe. Seventeen healthy laboratory staff (11 women, six men) who were not taking any drugs served as controls. Their mean age was 42 years (range 24-64).

Synovial fluid specimens were collected from inflamed knee joints by needle aspiration into EDTA tubes, when therapeutically indicated. In one patient knee joint aspirations were done twice (case Nos 1, 16) and in another patient both knees were aspirated (Nos 9, 10). The synovial fluid samples were immediately centrifuged ( 20 minutes, $2000 \mathrm{~g}$ ), and $2 \mathrm{ml}$ of the supernatants was treated with $0.3 \mathrm{ml}$ of perchloric acid $(4 \mathrm{~mol} / \mathrm{l})$ to remove protein. The excess perchloric acid in the supernatant was neutralised with a mixture of crystalline potassium carbonate and potassium phosphate. The specimens were centrifuged for five minutes and the supernatant kept frozen at $-20^{\circ} \mathrm{C}$ until analysed. EDTA plasma was treated in the same way.

Urate was analysed by reversed phase high performance liquid chromatography by direct injection of the neutralised supernatant. Hypoxanthine and xanthine in the supernatant were analysed similarly after precleaning on small cation exchange columns. These columns, $0.35 \times 2 \mathrm{~cm}$, were packed with Bio-Rad AG $50 \mathrm{~W} \times 12,200-400$ mesh in $\mathrm{H}^{+}$form. After application and rinsing the purines were eluted with $1.0 \mathrm{ml}$ of phosphoric acid, $4 \mathrm{~mol} / \mathrm{l}$. 
Table 1 Clinical data, roentgenological findings, and synovial fluid cells in patients with inflammatory arthritides

\begin{tabular}{|c|c|c|c|c|c|c|c|c|}
\hline \multirow{2}{*}{$\begin{array}{l}\text { Case } \\
\text { No }\end{array}$} & \multirow{2}{*}{$\begin{array}{l}\text { Age } \\
\text { (years) }\end{array}$} & \multirow[t]{2}{*}{ Sex } & \multirow{2}{*}{$\begin{array}{l}\text { Disease } \\
\text { duration } \\
\text { (years) }\end{array}$} & \multirow[t]{2}{*}{$x$ Ray } & \multirow[t]{2}{*}{ Diagnosis } & \multicolumn{3}{|c|}{ Synovial fluid cells } \\
\hline & & & & & & $\begin{array}{l}\text { Leucocytes } \\
\left(10^{12} / l\right)\end{array}$ & $\begin{array}{l}\text { PMNS } \\
(\%)\end{array}$ & $\begin{array}{l}\text { MNS } \\
(\%)\end{array}$ \\
\hline $\begin{array}{l}1^{*} \\
2 \\
3 \\
4 \\
5 \\
6 \\
7 \\
8 \\
9+ \\
10+ \\
11 \\
12 \\
13 \\
14 \\
15 \\
16^{*} \\
17 \\
18\end{array}$ & $\begin{array}{l}47 \\
52 \\
29 \\
21 \\
25 \\
32 \\
44 \\
43 \\
30 \\
30 \\
67 \\
41 \\
52 \\
32 \\
31 \\
47 \\
67 \\
68\end{array}$ & $\begin{array}{l}F \\
\mathbf{M} \\
\mathbf{F} \\
\mathbf{F} \\
\mathbf{F} \\
\mathbf{F} \\
\mathbf{M} \\
\mathbf{M} \\
\mathbf{F} \\
\mathbf{F} \\
\mathbf{F} \\
\mathbf{M} \\
\mathbf{M} \\
\mathbf{M} \\
\mathbf{F} \\
\mathbf{F} \\
\mathbf{F} \\
\mathbf{F}\end{array}$ & $\begin{array}{r}10 \\
4 \\
10 \\
18 \\
3 \\
9 \\
9 \\
10 \\
4 \\
4 \\
14 \\
9 \\
9 \\
16 \\
18 \\
10 \\
1 \\
0.5\end{array}$ & $\begin{array}{l}\text { No } \\
\text { No } \\
\text { No } \\
\text { No } \\
\text { ND } \\
\text { No } \\
\text { Yes } \\
\text { Yes } \\
\text { No } \\
\text { No } \\
\text { Yes } \\
\text { Yes } \\
\text { ND } \\
\text { No } \\
\text { No } \\
\text { No } \\
\text { No } \\
\text { No }\end{array}$ & $\begin{array}{l}\text { PsAS } \\
\text { RAS } \\
\text { RA } \\
\text { JRAS } \\
\text { RA } \\
\text { RA } \\
\text { PsA } \\
\text { PsA } \\
\text { RA } \\
\text { RA } \\
\text { RA } \\
\text { RA } \\
\text { RA } \\
\text { RA } \\
\text { JRA } \\
\text { PsA } \\
\text { RA } \\
\text { RA }\end{array}$ & $\begin{array}{r}22 \cdot 6 \\
12 \cdot 6 \\
10 \cdot 1 \\
16 \cdot 2 \\
33 \cdot 8 \\
15 \cdot 8 \\
13 \cdot 1 \\
5 \cdot 0 \\
11 \cdot 7 \\
12 \cdot 6 \\
4 \cdot 5 \\
13 \cdot 0 \\
4 \cdot 6 \\
8 \cdot 1 \\
5 \cdot 2 \\
4.5 \\
21 \cdot 5 \\
19 \cdot 2\end{array}$ & $\begin{array}{r}78 \\
86 \\
6 \\
6 \\
75 \\
65 \\
67 \\
32 \\
47 \\
47 \\
4 \\
67 \\
55 \\
77 \\
48 \\
57 \\
38 \\
77\end{array}$ & $\begin{array}{l}22 \\
14 \\
94 \\
94 \\
25 \\
35 \\
33 \\
68 \\
53 \\
53 \\
96 \\
33 \\
45 \\
23 \\
52 \\
43 \\
62 \\
23\end{array}$ \\
\hline
\end{tabular}

"Joint aspiration from the same knee of the same patient with a four month interval tLeft (No 9) and right (No 10) knee joint aspiration from the same patient. Ix Ray=radiographic destruction in the knee joint.

PSA=psoriatic arthritis; $\mathbf{R A}=$ rheumatoid arthritis; JRA = juvenile rheumatoid arthritis; $\mathbf{P M N}=$ polymorphonuclear; $M N=$ mononuclear.

The chromatographic system used consisted of a pump (Constametric model III, LDC, Florida), an ultraviolet absorbance detector (Spectromonitor III, LDC, Florida), a column $(300 \times 3.9 \mathrm{~mm})$ packed with $\mu$ Bondapak $\mathrm{Cl} 8$ (Waters Associates, Milford, MA 01757, USA), and a loop injector, $20 \mu \mathrm{l}$. Potassium phosphate buffer, $0.2 \mathrm{~mol} / \mathrm{l}$, pH 5.9, was used as the mobile phase and the flow was $1 \mathrm{ml} / \mathrm{min}$. Hypoxanthine, xanthine, and urate in the chromatogram (fig 1) were identified by comparing the peaks with the retention times for the pure substances and by the peak shift technique after adding the enzyme xanthine oxidase (Boehringer-Mannheim, Mannheim, Germany) to the specimens. Measurement of the oxypurines in synovial fluid and plasma was performed from standard curves of hypoxanthine, xanthine, and urate produced by peak height measurements of standard samples with known concentrations. The hypoxanthine and xanthine concentrations in healthy controls were $1 \cdot 1$ (SD $0.5) \mu \mathrm{mol} / \mathrm{l}$ and $0.4(0.1) \mu \mathrm{mol} / 1$, respectively. Further details of the chromatographic technique for oxypurine measurements are presented elsewhere. ${ }^{11}$

Figure 1 A typical high performance liquid chromatogram of hypoxanthine and xanthine from synovial fluid which has been deproteinised and precleaned on a cation exchange column. For chromatography conditions see text.

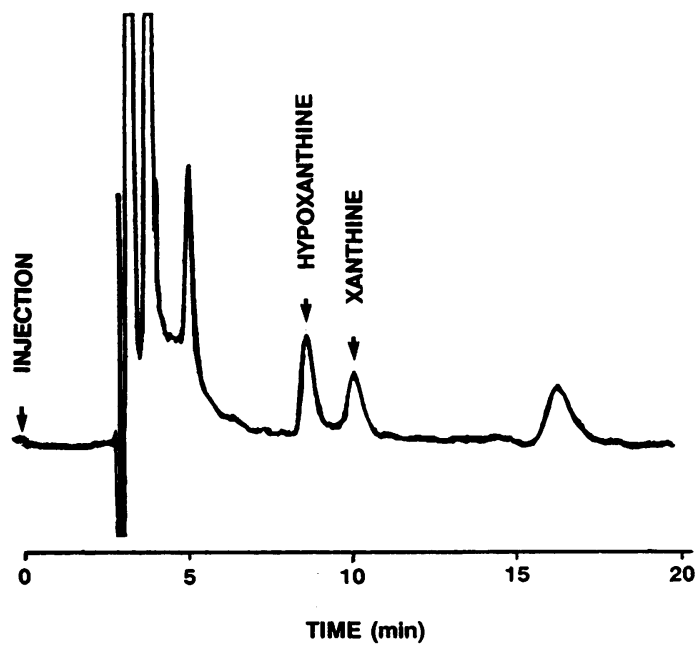

The inflammatory activity was estimated by measuring erythrocyte sedimentation rate according to Westergren (normal $<15 \mathrm{~mm} / \mathrm{h}$ ), C reactive protein (normal $<10 \mathrm{mg} / \mathrm{l}$ ), and haptoglobin (normal 0.2-1.4 g/1). Cell numbers and differential cell counting were performed on synovial fluids with routine methods.

\section{STATISTICS}

For statistical evaluation of differences between groups Student's $t$ test was used. Linear correlation analysis of data was used as indicated.

\section{Results}

Table 2 presents the plasma and synovial fluid concentrations of hypoxanthine, xanthine, and urate in patients with inflammatory arthritides. The mean synovial fluid concentrations of all oxypurine metabolites were higher in synovial fluid than in plasma. The plasma concentrations of hypoxanthine, xanthine, and urate were slightly higher in the patient group than in the healthy controls (table 2 ), but only the increase in plasma hypoxanthine reached significance $(\mathrm{p}<0.001)$. The measured metabolites in plasma or synovial fluid were not related to sex, age, or disease duration.

A weak relation was noted between the estimated effusion of knee joint and synovial fluid concentrations of hypoxanthine $(r=0.56$, $p<0.05)$ and xanthine $(r=0.052, p<0.05)$ respectively. Other subjective or objective clinical estimates of the arthritic condition were not related to the oxypurine metabolites in synovial fluid or plasma, except for a weak relation between morning stiffness and plasma urate $(r=0.58, p<0.05)$. The $x$ ray findings were discrete in most patients and only four had cartilage reduction but no destruction of the knee joint. The measured oxypurine concentrations were not related to the $x$ ray findings.

The median erythrocyte sedimentation rate was $27 \mathrm{~mm} / \mathrm{h}$ (range 5-120) and median C reactive protein $19 \mathrm{mg} / \mathrm{l}$ (range $<10-50$ ). Mean (SD) haptoglobin was $3 \cdot 2(1.0) \mathrm{g} / \mathrm{l}$ (range 1.28-4.24). Except for a weak correlation between synovial fluid urate and serum haptoglobin $(r=0.52, p<0.05)$ we found no relation between the concentrations of oxypurine metabolites and laboratory signs of systemic inflammatory activity. The local joint inflam-

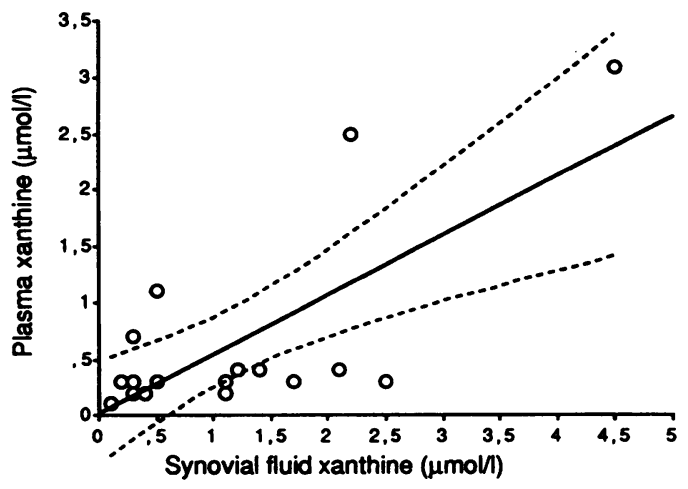

Figure 2 Concentration of xanthine in symovial fluid versus the plasma concentration of xanthine in patients with inflammatory arthritides $(r=0.71, p<0.001)$. 
Table 2 Mean (SD) hypoxanthine, xanthine, and urate concentrations in plasma and in synovial fluid samples from 16 patients with inflammatory arthritides and in plasma from I7 control subjects

\begin{tabular}{|c|c|c|c|c|}
\hline \multirow[t]{2}{*}{ Metabolite } & \multirow{2}{*}{$\frac{\text { Controls }(n=17)}{\text { Plasma }}$} & \multicolumn{2}{|c|}{ Patients ( $n=16)$} & \multirow{2}{*}{$\begin{array}{l}\text { Correlation } \\
\text { coefficientst }\end{array}$} \\
\hline & & $\begin{array}{l}\text { Plasma } \\
(\mu m o l l l) \\
(n=17)\end{array}$ & $\begin{array}{l}\text { Synovial } \\
\text { fluid } \\
\text { ( } \mathrm{nmol} / \mathrm{l}) \\
(n=18)\end{array}$ & \\
\hline $\begin{array}{l}\text { Hypoxanthine } \\
\text { Xanthine } \\
\text { Urate }\end{array}$ & $\begin{array}{l}1 \cdot 1(0.5)^{*} \\
0.4(0.1) \\
194(41)\end{array}$ & $\begin{array}{l}2 \cdot 1(1 \cdot 5)^{*} \\
0.7(0.9) \\
215(64)\end{array}$ & $\begin{array}{l}2 \cdot 3(1 \cdot 8) \\
1.2(1 \cdot 1) \\
229(74)\end{array}$ & $\begin{array}{l}0.11 \\
0.71^{*} \\
0.76^{*}\end{array}$ \\
\hline
\end{tabular}

${ }^{*} \mathrm{p}<0.001$.

fCorrelation coefficients between plasma and synovial fluid concentrations of the respective metabolite. $x$ ray findings of the joints. Except for a weak correlation between synovial fluid urate and serum haptoglobin we found no relation between the laboratory markers of inflammatory activity and oxypurine concentrations in plasma or synovial fluid.

During catabolism hypoxanthine is converted to xanthine and then to urate by xanthine oxidase. If this enzyme was absent in the joint, xanthine and hypoxanthine would be the end products of purine metabolism of the joint, rather than urate. Xanthine oxidase was previously thought to be almost exclusively found in the liver and intestinal mucosa in man. ${ }^{12}$ The presence of increased concentrations of xanthine oxidase was recently reported in the synovial tissue from patients with rheumatoid arthritis. ${ }^{13}$ In our study the ratio between synovial fluid and plasma concentrations of xanthine and urate was found to be $>1 \cdot 0$, which may support the presence of xanthine oxidase within the inflamed joint cavity. The increases of the synovial fluid concentrations were fairly small, however, compared with the plasma concentrations and the differences may partly be due to analytical differences in processing two different biological materials. One possible source of xanthine oxidase in the inflamed joint cavity might be the large number of invading inflammatory cells. We found no correlation between the cell counts or the appearance of oxypurines in synovial fluid, however.

Purine metabolites in inflamed synovial fluid may result from adenosine 5-triphosphate catabolism in senescent joint cells like neutrophils, lymphocytes, or cells from pannus. Degradation of DNA and other cellular substances containing purine metabolites may also occur in necrotic lesions of the inflamed synovia. Finally, the appearance of increased concentrations of purine bases in synovial fluid may be due to ischaemia in joint structures.

It has been known for several years that increased catabolism of nucleotides occurs during tissue hypoxia. ${ }^{14} 15$ Hypoxanthine in plasma has been proposed to be a good indicator of tissue hypoxia. ${ }^{16} 17$ Local accumulation of degradation products from the nucleotide pool is also reported to occur in ischaemic organs. Clinical studies in patients with cerebral ischaemia have reported considerable increases of hypoxanthine and xanthine concentrations in the cerebrospinal fluid. ${ }^{18}$ During persistent synovial inflammation with effusion, hypoxia in the synovial cavity is reported. ${ }^{19}$ Reduction of the oxygen tension has been attributed to pressure changes induced by exercise. The blood supply to the synovium is supposed to be transiently reduced owing to the increased pressure. Thus the appearance of increased synovial fluid concentrations of hypoxanthine, xanthine, and urate may reflect ischaemic damage in the joint due to increased joint pressure. In support of this hypothesis we found that the estimated effusion of the investigated knee joint correlated with its synovial fluid concentrations of hypoxanthine and xanthine. The tissue damage associated with temporary ischaemia may partly be dependent on the production of free radicals by the oxypurines. The concentrations of hypoxanthine, xanthine, or urate in plasma or synovial fluid were not related to the disease duration or 
xanthine/xanthine oxidase system..$^{20-22}$ In this context it is worth noting that thiol groups found, for example, in penicillamine and gold compounds interfere with this free radical generating system.

This study was supported by the Swedish Medical Research Council.

1 McConkey B, Crockson R A, Crockson A P, Williamson A R The effects of some anti-rheumatic drugs on the acute-
phase proteins in rheumatoid arthritis. $Q \mathcal{F}$ Med $1973^{\prime}, 42$ : phase prote

2 Pullar T, Capell H A. Can treatment really influence the radiological progression of rheumatoid arthritis? $\mathrm{Br} \mathcal{F}$ Rhermatol 1986; 25: 2-6.

3 Fassbender $\mathbf{H ~ G}$. Current understanding of rheumatoid arthritis. Inflammation 1984; 8 (suppl): 527-42.

4 Barret A J, Saklatvala J. Proteinase in joint disease. In Kelley W N, Harris E D, Ruddy S, Sledges C B, eds. Textbook of rheumatology. 2nd ed. Philadelphia: Saunders, 1985: 182-92.

5 Shiozawa S, Shiozawa K, Fuzita T. Morphologic observation in the early phase of the cartilage-pannus junction. Ligh and electronmicroscopic studies of active cellular pannus. and electronmicroscopic studies

6 Woolley D E, Crossley M J, Evanson J M. Collagenase at sites of cartilage erosion in the rheumatoid joint. Arthritis Rheum 1977; 20: 1231-9.

7 Cleland L D. Oxy radicals, "peroxide tone" and inflam mation. F Rheumatol 1984; 11: 725-6.

8 Jubb R W. Breakdown of articular cartilage by vascula tissue. $\mathcal{F}$ Pathol 1982; 136: 333-43.

9 Herbert K E, Scott D L, Perrett D. Nucleosides and bases in synovial fluid from patients with rheumatoid arthritis and osteoarthritis. Clin Sci 1988; 74: 97-9.
10 Arnett F C, Edworthy S M, Bloch D A, et al. The American Rheumatism Association 1987 revised criteria for the classification of rheumatoid arthritis. Arthritis Rheum 1988; 31: 315-24.

11 Niklasson F. Simultaneous liquid-chromatographic determination of hypoxanthine, xanthine, urate and creatinine in cerebrospinal fluid, with direct injection. Clin Chem 1983; 29: 1543-6.

12 Watts R W E, Watts J E M, Seegmiller J E. Xanthine oxidase activity in human tissue and its inhibition by allopurinol. activity in human tissue and its in

13 Allen R E, Outhwaite J, Morris C J, Blake D R. Xanthine oxido-reductase activity in human synovium. $\mathrm{Br} \mathcal{f}$ Oxido-reductase activity in huma

14 Bern R M. Cardiac nucleotides in hypoxia: possible role in regulation of coronary blood flow. Am $\mathcal{F}$ Physiol 1963; 204:

15 Bern R M, Rubio R, Curnish R R. Release of adenosine from ischemic brain. Circ Res 1974; 35: 262-71.

16 Saugstad O D. Hypoxanthine as a measurement of hypoxia. Pediat Res 1975; 9: 158-61

17 Saugstad $O \mathrm{D}$. The determination of hypoxanthine and xanthine with a pO 2 electrode. Pediatr Res 1975; 9: 575-9.

18 Hällgren R, Niklasson F, Terent A, Ákeblom Á, Widerlöv E. Oxypurines in cerebrospinal fluid as indices of disturbed brain metabolism. A clinical study of ischemic brain brain metabolism. A clinical stures. Stroke 1983; 14: 382-8.

19 Woodruff T, Blake D R, Freeman J, Andreus F J, Salt P, Lunec J. Is chronic synovitis an example of reperfusion injury? Ann Rheum Dis 1986; 45, 608-11.

20 Battelli M G, Corte E D, Stirpe F. Xanthine oxidase type D (dehydrogenase) in the intestine and other organs of rat. Biochem $\mathcal{F}$ 1972; 126: 747-9.

21 Parks D A, Bulkley G B, Granger D N. Role of oxygenderived free radicals in digestive tract diseases. Surgery 1983; 94: 415-22.

22 Chambers D E, Parkers D A, Pettersson G. Xanthine oxidase as a source of free radical damage in myocardial ischemia. 于 Mol Cell Cardiol 1985; 17: 145-52. 